\title{
Prevention of acute chemotherapy-induced nausea and vomiting: the role of palonosetron
}

\author{
This article was published in the following Dove Press journal: \\ Cancer Management and Research \\ 10 August 2009 \\ Number of times this article has been viewed
}

\section{Emilio Bajetta \\ Sara Pusceddu \\ Valentina Guadalupi \\ Monika Ducceschi \\ Luigi Celio}

Medical Oncology Unit 2, Fondazione IRCCS "Istituto Nazionale dei Tumori", Milan, Italy
Correspondence: Emilio Bajetta

Medical Oncology Unit 2, Fondazione IRCCS "Istituto Nazionale dei Tumori", Via Venezian I, 20133 Milan, Italy

Tel +3902 23902500

$\mathrm{Fax}+390223902149$

Email emilio.bajetta@istitutotumori.mi.it

\begin{abstract}
Prevention of nausea and vomiting is the main goal of antiemetic treatment in cancer patients scheduled to receive chemotherapy. To prevent acute emesis, antiemetics should be administered just before chemotherapy and patients should be protected for up to 24 hours after chemotherapy initiation. The emetogenic potential of chemotherapeutic agents guides clinicians towards the most appropriate antiemetic prophylaxis. Current guidelines recommend the use of 5- $\mathrm{HT}_{3}$ receptor antagonist (RA) either alone or in combination with dexamethasone and/or a neurokinin-1

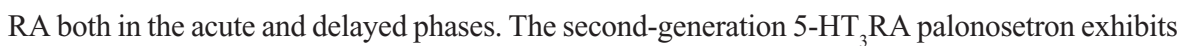
a longer half-life and a higher binding affinity than older antagonists. Palonosetron has been approved by the FDA for the prevention of chemotherapy-induced nausea and vomiting (CINV) in patients scheduled to receive either moderately (MEC) or highly emetogenic chemotherapy (HEC) and for the prevention of delayed CINV in patients receiving MEC. The present review will discuss the role of palonosetron in the prevention of acute CINV.
\end{abstract}

Keywords: antiemetics, chemotherapy, nausea, vomiting, serotonin-receptor antagonists, palonosetron

\section{Introduction}

Cancer treatments give rise to additional acute and chronic symptoms that may severely impair quality of life. Nausea and vomiting are among the most common and unpleasant side effects of chemotherapy. ${ }^{1}$ Despite advances in both cytotoxic agents and supportive care treatments patients undergoing chemotherapy may still suffer from nausea and vomiting. ${ }^{2}$

The most clinically relevant antiemetic drugs are serotonin $\left(5-\mathrm{HT}_{3}\right)$ receptor antagonists (5-HT 3 RA), neurokinin-1 receptor antagonists (NK-1RA), and corticosteroids. ${ }^{3}$ At present, several 5- $\mathrm{HT}_{3}$ RAs are commercially available for the management of chemotherapy-induced nausea and vomiting (CINV). This drug class includes the first-generation agents (ie, granisetron, ondansetron, tropisetron and dolasetron), and the novel second-generation antagonist palonosetron. The present review will discuss the role of palonosetron in the prevention of acute CINV.

\section{Phases of CINV}

Traditionally, CINV has been classified as acute or delayed based its temporal onset following chemotherapy. Acute CINV occurs within the first 24 hours after chemotherapy initiation, while delayed emesis occurs between days 2 to 5 (24 to 120 hours postchemotherapy). ${ }^{4}$ It should be noted that the strongest predictor of delayed CINV is the occurrence of symptoms in the acute phase, but delayed emesis arises in the absence 
of acute symptoms in $18 \%$ to $24 \%$ of patients..$^{5}$ Patients who are not sufficiently protected from emesis during the first chemotherapy cycle are also at high risk of developing anticipatory nausea and vomiting. ${ }^{6}$ Anticipatory CINV is observed in patients whose emetic episodes are triggered by taste, odor sight, thoughts, or anxiety that is secondary to a history of poor response to antiemetic agents or inadequate antiemetic prophylaxis in the previous course of chemotherapy. ${ }^{7}$ Therefore adequate protection against CINV, starting from the first cycle of chemotherapy, is paramount to successful control of subsequent cycle emesis. ${ }^{3}$

\section{Risk factors for CINV}

The severity of CINV is influenced by two different risk factors, namely chemotherapy and individual patient characteristics (Figure 1). Antiemetic prophylaxis is given in relation to the emetogenic potential of the chemotherapy regimen, which has an intrinsic propensity to cause CINV, the severity of which depends on the class and dose of drugs administered. Intravenously administered cytotoxic agents were initially assigned to five levels of emetogenicity. ${ }^{7}$ More recently, chemotherapeutic agents have been divided into four emetic risk categories according to the percentage of patients having emetic episodes when no prophylactic antiemetic protection is provided: high $(>90 \%)$, moderate (30\% to $90 \%)$, low $(10 \%$ to $30 \%)$, and minimal $(<10 \%){ }^{8,9}$ In addition to the emetogenicity of chemotherapy, several patient-related factors may increase the risk of CINV. These factors include a young age, female gender, history of low or no alcohol intake, experience of emesis during pregnancy, impaired quality of life, and previous experience with chemotherapy. 3,10

\section{Physiopathology}

Although multiple neurotransmitters are involved in emetic pathways, dopamine, 5- $\mathrm{HT}_{3}$, substance $\mathrm{P}$, and their corresponding receptors play a key role in the onset of CINV. ${ }^{11}$ Receptors for these transmitters are found in high numbers in the dorsal vagal complex, area postrema, and gastrointestinal tract; drugs that interact with these neurotransmitter systems have been shown to be effective therapeutics for CINV. Chemotherapy damages the gastrointestinal tract and activates abdominal vagal afferents. Under drug stimulus, the enterochromaffin cells of the gastrointestinal mucosa release $5-\mathrm{HT}_{3}$, which binds its receptor on the vagal afferent neurons. The binding between $5-\mathrm{HT}_{3}$ and its receptor stimulates two specific areas in the central nervous system both located in the medulla: the chemoreceptor trigger zone (CTZ) and the vomiting center (VC). The CTZ is activated via blood or cerebrospinal fluid and invokes the release of various neurotransmitters, which stimulate the VC. Once activated, the $\mathrm{VC}$ modulates the efferent transmission to the respiratory, vasomotor, and salivary centers as well as to the abdominal

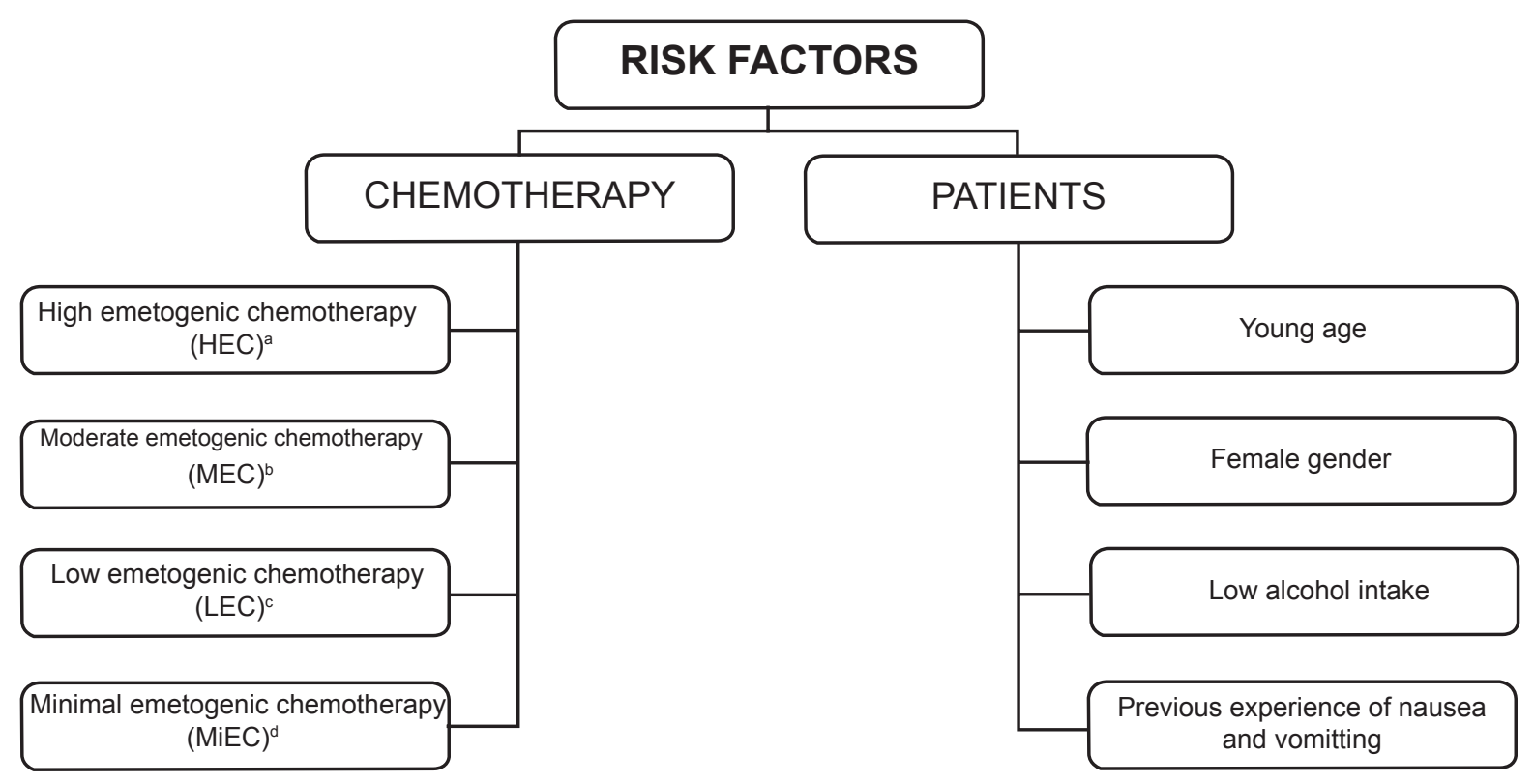

Figure I Risk factors influencing the severity of chemotherapy-induced nausea and vomiting. a'Examples of HEC agents: cisplatin $\geq 50 \mathrm{mg} / \mathrm{m}^{2}$, cyclophosphamide $>1.5 \mathrm{~g} / \mathrm{m}^{2}$, dacarbazine, carmustine. 'Examples of MEC agents: carboplatin, cyclophosphamide,doxorubicin, epirubicin, irinotecan, oxaliplatin. 'Examples of LEC agents: etoposide, cetuximab, paclitaxel, topotecan, trastuzumab, bortezomib.

'Examples of MiEC agents: bevacizumab, bleomycin, vinblastine, vinorelbine. 
muscles, diaphragm, and esophagus, resulting in emesis. The primary site of action of 5- $\mathrm{HT}_{3} \mathrm{RA}$ is at the abdominal vagal afferents. ${ }^{12}$ Cytotoxic agents and other toxins increase release of $5-\mathrm{HT}_{3}$, which subsequently activates its receptors. 5-HT ${ }_{3}$ RA abolishes the signal to the receptors associated with vagal afferents. In contrast, NK-1RA acts at the dorsal vagal complex in the medulla, inhibiting gastric emptying. 5- $\mathrm{HT}_{3}$ receptors are also expressed centrally in the area postrema and in the nucleus tractus solitarii; thus 5- $\mathrm{HT}_{3} \mathrm{RA}$ also acts centrally, in synergy with the NK-1RA, which acts in brain regions. ${ }^{13,14}$

Initial clinical results with first-generation 5- $\mathrm{HT}_{3} \mathrm{RAs}$ led to the belief that serotonin plays a pivotal role in mechanisms underlying acute emesis. Indeed, it was hypothesized that the acute protection from CINV was mediated largely through attenuation of peripheral $5-\mathrm{HT}_{3}$ receptors on the vagal afferents. Antiemetic treatment for the acute CINV is ineffective without the use of 5-HT ${ }_{3}$ RA. ${ }^{11,12}$

\section{Antiemetic therapy}

Different drug classes are available for the prevention of CINV, but the three most commonly used classes include

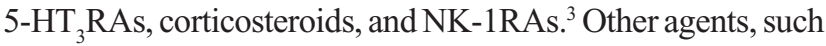
as antihistamines and anticholinergics, are used infrequently due to their lacking antiemetic properties in CINV. ${ }^{15}$ As a class, 5-HT 3 RAs have very favorable antiemetic properties and are not associated with dopamine-related side effects. ${ }^{12}$ As a result, these antagonists have become the mainstay of current antiemetic therapy. In the early 1980s, vomiting and nausea were ranked as the two most feared side effects of chemotherapy. ${ }^{16}$ In the 1990 s, after the introduction of the firstgeneration 5-HT $\mathrm{HA}_{3} \mathrm{RAs}$, nausea was scored the most feared side effect, whereas vomiting only ranked as number five. ${ }^{17,18}$

Aprepitant is the first commercially available NK-1RA, and its addition to a $5-\mathrm{HT}_{3} \mathrm{RA}$ and dexamethasone is currently recommended to prevent delayed CINV in patients treated with highly emetogenic chemotherapy (HEC) or anthracycline and cyclophosphamide (AC)-based regimens. ${ }^{3}$ The drug has a good safety profile, but its inhibitory effect on the CYP3A4 enzyme requires dose adjustment with other substrates of CYP3A4, including dexamethasone and warfarin. ${ }^{19}$ It is thought that corticosteroids such as dexamethasone and methylprednisolone suppress CINV by limiting peritumoral inflammation and prostaglandin production. ${ }^{20}$ Corticosteroids are the most frequently used drug to prevent delayed CINV, since multiple-day administration of a first-generation $5-\mathrm{HT}_{3} \mathrm{RA}$ to prevent delayed emesis is not recommended in current antiemetic guidelines. . $, 21,22$
With repeated courses of chemotherapy, emesis becomes progressively more difficult to control, although adequate control in the first cycle of chemotherapy is more likely to be associated with control of acute CINV in subsequent cycles. ${ }^{20}$ Uncontrolled emesis associated with chemotherapy can lead to such a negative experience that patients may refuse potentially life-saving treatment for their malignancy. Moreover, CINV can result in dehydration, electrolyte imbalance, and malnutrition, which can also affect patient's quality of life. Therefore, control of nausea and vomiting starting from the first chemotherapy cycle plays an integral role in the overall treatment success for the cancer patient.

\section{Antiemetic guidelines}

Prevention of acute and delayed CINV is the main goal of antiemetic therapy in cancer patients who are scheduled to receive emetogenic chemotherapy. Antiemetic guidelines have been released by several organizations including the Multinational Association of Supportive Care in Cancer (MASCC), the American Society of Clinical Oncology, and the National Comprehensive Cancer Network. ${ }^{9,21,22}$ MASCC guidelines, that are endorsed by nine international oncology groups, divide chemotherapeutic agents into four emetic risk groups, and provide treatment recommendations for each group. The goal in the prophylaxis of acute CINV is to avoid any experience of nausea and vomiting within 24 hours after chemotherapy initiation. In general, the international guidelines for the prevention of acute CINV have attempted to indicate a common antiemetic scheme that includes the use of 5- $\mathrm{HT}_{3} \mathrm{RA}$ in combination with dexamethasone, with or without NK-1RA.

In recent years, antiemetic recommendations have changed according to relevant information available from clinical experience as well as data from controlled trials. The implementation of guidelines is therefore ongoing as new clinical data and new antiemetic agents become available. The latest version of MASCC guidelines was published in 2006, but Herrstedt has recently summarized recommendations from the updated version of the guidelines, which are also available at the MASCC website (www.mascc.org). ${ }^{6}$ Current MASCC recommendations for the prevention of acute CINV following HEC and MEC are summarized in Table 1.

\section{Acute CINV}

Acute CINV occurs within 24 hours after chemotherapy initiation, and the highest risk of emesis is within the first 4 hours of treatment. Cytotoxic agents such as cisplatin are 
Table I MASCC guidelines for the prevention of acute chemotherapy-induced nausea and vomiting following HEC and MEC $^{6}$

\begin{tabular}{ll}
\hline Emetic risk category & $\begin{array}{l}\text { Recommended antiemetic } \\
\text { regimen on day I (administered } \\
\text { prior to chemotherapy) }\end{array}$ \\
\hline HEC & $5-\mathrm{HT}_{3}$ receptor antagonist \\
& + Dexamethasone \\
& $+\mathrm{NK}-\mathrm{I}$ receptor antagonist \\
& $5-\mathrm{HT}_{3}$ receptor antagonist \\
MEC & + Dexamethasone \\
(anthracycline and & $+\mathrm{NK}-\mathrm{I}$ receptor antagonist \\
cyclophosphamide-based) & $5-\mathrm{HT}_{3}$ receptor antagonist \\
MEC & + Dexamethasone \\
\hline
\end{tabular}

Abbreviations: MASCC, Multinational Association of Supportive Care in Cancer; HEC, highly emetogenic chemotherapy; MEC, moderately emetogenic chemotherapy.

associated with an intense acute phase of emesis occurring on day 1 , followed by a less intense delayed phase. Other agents such as cyclophosphamide and carboplatin are associated with less intense acute phase, but a more persistent delayed phase. ${ }^{23}$ In case of multiple-drug chemotherapy regimens, the emetogenic potential of the most emetic drug should be taken into account in the selection of antiemetic treatment, but an increased emetic potential of the chemotherapy regimen as a whole should also be considered (eg, single agents anthracycline and cyclophosphamide have moderate emetic potential but the combination exhibits high emetic potential). Patient-related risk factors should also be taken into account when assessing the risk of acute CINV. For patients undergoing multiple-day chemotherapy, it is difficult to establish whether the onset of the emesis is acute or delayed, due to the overlap of both events. At each day of chemotherapy, a new stimulus of acute CINV appears and, in this setting, the tailoring of antiemetic treatment is more complex..$^{23} \mathrm{In}$ multiple-day chemotherapy regimens, antiemetic prophylaxis should achieve long-lasting inhibition of the $5-\mathrm{HT}_{3}$ receptors due to the persistence of the emetic stimulus throughout the entire chemotherapy cycle.

\section{Prophylaxis of acute CINV}

To prevent acute emesis, antiemetic treatment should be administered just before chemotherapy and patients should be protected for up to 24 hours following chemotherapy initiation. Current guidelines recommend the use of a $5-\mathrm{HT}_{3} \mathrm{RA}$ as part of the antiemetic prophylaxis for acute CINV after HEC or moderately emetogenic chemotherapy (MEC). ${ }^{6,21,22}$ Selection of the appropriate antiemetic treatment to be administered prior to chemotherapy is influenced by the following emetic risk groups:
High emetic risk group: patients should be given a combination of 5-HT $\mathrm{HA}_{3}$, dexamethasone, and NK-1RA. Patients who are scheduled to receive an AC-based chemotherapy should be given the same antiemetic prophylaxis.

Moderate emetic risk group: patients should be given a 5-HT $\mathrm{RA}_{3}$ in combination with dexamethasone.

Low emetic risk group: patients should receive a low dose of dexamethasone.

The antiemetic guidelines do not differentiate among the 5-HT RAs, suggesting that they have similar efficacy. A meta-analysis of randomized trials was conducted to compare efficacy of the first-generation 5- $\mathrm{HT}_{3} \mathrm{RAs}$ for the prevention of acute CINV in patients receiving cisplatin- and noncisplatin-based chemotherapy. ${ }^{24}$ The authors concluded that antiemetic efficacy of these antagonists was comparable in the acute phase. The second-generation 5- $\mathrm{HT}_{3} \mathrm{RA}$ palonosetron was only briefly mentioned in that review, as very few comparative trials were available for the analysis at that time.

\section{Palonosetron}

Palonosetron is a new second-generation 5- $\mathrm{HT}_{3} \mathrm{RA}$ that showed better protection than older antagonists against CINV following MEC in the FDA registration trials. ${ }^{25,26}$ Palonosetron is approved by Health Authorities for the prevention of acute and delayed CINV at a dose of $0.25 \mathrm{mg}$ intravenously administered prior to chemotherapy. It also should be noted that palonosetron is the only $5-\mathrm{HT}_{3} \mathrm{RA}$ that received the FDA approval for the prevention of delayed CINV following MEC. A recently reported randomized phase III trial conducted in Japan demonstrated that palonosetron in combination with dexamethasone is significantly more efficacious than is the combination of granisetron and dexamethasone in the prevention of delayed CINV following HEC. ${ }^{27}$

\section{Pharmacological profile}

In comparison with older 5-HT RAs which exhibit halflives in the range of 4-9 hours, palonosetron has a longer mean elimination half-life of approximately 40 hours. ${ }^{28}$ Palonosetron also has a higher binding affinity for the $5-\mathrm{HT}_{3}$ receptor that is at least 30 -fold higher than the first-generation setrons.

\section{Mechanism of action}

The nature of the interaction of palonosetron with the $5-\mathrm{HT}_{3}$ receptor has recently been investigated. ${ }^{29}$ The antagonism of palonosetron is due to allosteric inhibition of the receptor. In contrast, ondansetron and granisetron engage in competitive 
antagonism of the $5-\mathrm{HT}_{3}$ receptor. Structural studies have also indicated that palonosetron exhibits positive cooperativity, in contrast to ondansetron and granisetron which exhibit simple bimolecular interactions. Differential reduction in binding at cell surfaces is consistent with palonosetron triggering either $5-\mathrm{HT}_{3}$ receptor internalization or inactivation.

\section{Safety profile}

A single dose of palonosetron has been found to have a tolerability profile comparable to other drug class members; headache, constipation, and dizziness were the most commonly reported adverse events. In March 2008 and February 2009 the FDA and EMEA, respectively, updated the prescribing information of palonosetron with additional cardiac safety results from a randomized, double-blind, placebo- and moxifloxacin-controlled dose-response study on 230 healthy volunteers, specifically focusing on changes in the QT interval. ${ }^{30,31}$ Single doses of intravenous palonosetron ranging from 0.25 to $2.25 \mathrm{mg}$ were assessed. There was no dose-related electrocardiograph effects or any evidence of QTc interval prolongation. ${ }^{32}$

\section{Registration trials}

The efficacy and safety of a fixed, single intravenous dose of palonosetron in preventing CINV have been assessed in five phase I, one phase II, and three phase III trials. ${ }^{33}$

Two randomized, double-blind, phase III, noninferiority trials comparing palonosetron with ondansetron or dolasetron in patients who received MEC demonstrated the efficacy of palonosetron compared with first-generation 5-HT 3 RAs. The primary endpoint of both studies was the proportion of patients achieving a complete response (CR; no emesis and no rescue medication) during the acute phase following the first cycle of chemotherapy. Gralla et al compared single intravenous doses of palonosetron $(0.25 \mathrm{mg}$ and $0.75 \mathrm{mg})$ with a single intravenous dose of ondansetron (32 mg), while Eisenberg et al compared palonosetron with a single intravenous dose of dolasetron $(100 \mathrm{mg}){ }^{25,26}$ Results of both trials showed that palonosetron is noninferior to, or more efficacious than are older antagonists in the prevention of acute and delayed CINV after MEC. A third trial with an identical noninferiority design using HEC compared single intravenous doses of palonosetron with a single dose of ondansetron immediately prior to chemotherapy. ${ }^{34}$ In this study, palonosetron resulted noninferior to ondansetron in the prevention of CINV during the acute, delayed, and overall phases.

In the registration trials, both palonosetron doses $(0.25 \mathrm{mg}$ and $0.75 \mathrm{mg})$ were noninferior to ondansetron or dolasetron for the prevention of acute CINV after MEC. Therefore, the lowest fully effective palonosetron dose was approved by the FDA.

\section{Palonosetron for the prevention of acute CINV}

A number of clinical trials have demonstrated that palonosetron provides a high protection against the acute CINV after MEC and HEC regimens (Table 2). A pooled analysis of the two registration trials using MEC showed that palonosetron induces a statistically significant improvement in the CR rate during the acute phase compared with pooled data from patients who received ondansetron or dolasetron ( $72 \%$ versus $61 \%$, respectively). ${ }^{36}$ In addition, within the combined cohort of patients pretreated with palonosetron, significantly higher proportion of emesis-free patients was observed than those receiving ondansetron or dolasetron during the acute phase after MEC (79\% versus 65\%). ${ }^{37,38}$

Analysis of pooled data from registration trials using MEC was performed to assess the hypothesis that the ability of palonosetron to prevent delayed CINV could be simply a carryover effect from better control of symptoms in the acute phase. ${ }^{38}$ Among emesis-free patients in the acute phase, a significantly greater proportion receiving palonosetron experienced no delayed CINV compared with those who received ondansetron or dolasetron $(80 \%$ versus $69 \%$, respectively). A similar trend was noted for those patients who had acute CINV. These findings suggest that the improved ability of palonosetron to prevent delayed CINV is unlikely to be simply a carryover effect and highlight the differentiating features of palonosetron in exerting a direct effect in the delayed phase, a unique characteristic among the agents from the same drug class.

In a noninferiority phase III trial published in 2006, single agent palonosetron was demonstrated to be at least as effective as ondansetron in preventing acute CINV from HEC; the CR rates were slightly higher with palonosetron than ondansetron during the delayed and overall phases. ${ }^{34}$ It is worth to note that $67 \%$ of the patients in that study also received prophylactic dexamethasone $20 \mathrm{mg}$ only prior to chemotherapy. In this subgroup of patients, there was a not statistically significant improvement in the acute $\mathrm{CR}$ rate in favour of the palonosetron group over the ondansetron group (65\% versus 56\%). It also should be noted that patients pretreated with palonosetron who also received dexamethasone had significantly higher CR rates than those receiving ondansetron plus dexamethasone, during both the delayed (42\% versus 29\%) and overall 
Table 2 Prevention of acute chemotherapy-induced nausea and vomiting: results of clinical trials with palonosetron

\begin{tabular}{|c|c|c|c|c|c|}
\hline Reference & $\begin{array}{l}\text { No. of } \\
\text { patients }\end{array}$ & $\begin{array}{l}\text { Emetic risk } \\
\text { category }\end{array}$ & $\begin{array}{l}\text { Antiemetic } \\
\text { regimen } \\
\text { on Day I }\end{array}$ & CR (\%) & $\begin{array}{l}\text { Emesis-free } \\
\text { patients (\%) }\end{array}$ \\
\hline \multicolumn{6}{|c|}{ Randomized studies } \\
\hline Gralla $2003^{25}$ & 189 & MEC & $\begin{array}{l}\text { Palo } 0.25 \mathrm{mg} \\
{ }^{\mathrm{a} D e x} 20 \mathrm{mg}\end{array}$ & 81 & 85 \\
\hline Eisenberg $2003^{26}$ & 189 & $M \mathrm{MC}^{\mathrm{b}}$ & $\begin{array}{l}\text { Palo } 0.25 \mathrm{mg} \\
{ }^{\mathrm{a} D e x} 20 \mathrm{mg}\end{array}$ & 64 & 72 \\
\hline Aapro $2006^{34}$ & 223 & HEC & $\begin{array}{l}\text { Palo } 0.25 \mathrm{mg} \\
\text { aDex } 20 \mathrm{mg}\end{array}$ & 59 & 68 \\
\hline Yu $2009^{35}$ & 104 & HEC & Palo $0.25 \mathrm{mg}$ & 83 & NA \\
\hline Saito $2009^{27}$ & 239 & MEC (AC-based) & $\begin{array}{l}\text { Palo } 0.75 \mathrm{mg} \\
\text { Dex } 16 \mathrm{mg}\end{array}$ & 69 & NA \\
\hline Saito $2009^{27}$ & 316 & HEC & $\begin{array}{l}\text { Palo } 0.75 \mathrm{mg} \\
\text { Dex } 16 \mathrm{mg}\end{array}$ & 80 & NA \\
\hline \multicolumn{6}{|c|}{ Nonrandomized studies } \\
\hline Grote $2006^{43}$ & 58 & $M C^{c}$ & $\begin{array}{l}\text { Palo } 0.25 \mathrm{mg} \\
\text { Dex } 12 \mathrm{mg} \\
\text { Apr } 125 \mathrm{mg}\end{array}$ & 88 & 93 \\
\hline Navari $2007^{47}$ & 32 & MEC & $\begin{array}{l}\text { Palo } 0.25 \mathrm{mg} \\
\text { Dex } 8 \mathrm{mg} \\
\text { Olanzapine } 10 \mathrm{mg}\end{array}$ & 97 & 97 \\
\hline Giuliani $2008^{40}$ & 85 & MEC & $\begin{array}{l}\text { Palo } 0.25 \mathrm{mg} \\
\text { Dex } 8 \mathrm{mg}\end{array}$ & 99 & 99 \\
\hline Grunberg $2008^{45}$ & 41 & MEC & $\begin{array}{l}\text { Palo } 0.25 \mathrm{mg} \\
\text { Dex } 20 \mathrm{mg} \\
\text { Apr } 285 \mathrm{mg}\end{array}$ & 76 & 100 \\
\hline Lorusso $2009^{39}$ & 35 & HEC & $\begin{array}{l}\text { Palo } 0.25 \mathrm{mg} \\
\text { Dex } 20 \mathrm{mg}\end{array}$ & 86 & NA \\
\hline
\end{tabular}

${ }^{a}$ Corticosteroid given at the discretion of the investigator; b the cohort includes 120 patients receiving AC-based chemotherapy; ${ }^{c}$ the cohort includes 24 patients receiving AC-based chemotherapy.

Abbreviations: CR, complete response; MEC, moderately emetogenic chemotherapy; HEC, highly emetogenic chemotherapy; AC, anthracycline and cyclophosphamide; Palo, palonosetron, Dex, dexamethasone; Apr, aprepitant; NA, not available.

( $41 \%$ versus $25 \%$ ) phases after chemotherapy. Therefore, the investigators stated that palonosetron administered with dexamethasone, as per current antiemetic guidelines, was significantly more effective than ondansetron plus dexamethasone in preventing CINV during the overall 5-day period after HEC.

A recently reported multicenter, double-blind, phase III trial conducted in Japan evaluated the efficacy and safety of intravenous single dose of palonosetron $(0.75 \mathrm{mg})$ versus intravenous single dose of granisetron $(40 \mu \mathrm{g} / \mathrm{kg})$ for the prevention of CINV, both of which were administered with dexamethasone in patients who were scheduled to receive HEC or AC-based chemotherapy. ${ }^{27}$ Primary endpoints were the proportion of patients with a CR during the acute phase (noninferiority comparison with granisetron) and the proportion of patients with a $\mathrm{CR}$ during the delayed phase (superiority comparison with granisetron). A total of 418 of
555 patients $(75 \%)$ in the palonosetron group achieved CR during the acute phase compared with 410 of 559 patients $(73 \%)$ in the granisetron group (mean difference $2.9 \%$ [95\% CI, -2.70 to 7.27$]$ ).

In contrast to the older 5-HT $\mathrm{HAs}_{3}$, palonosetron has been shown to effectively control nausea, which remains one of the major unmet needs in management of emesis. Palonosetron achieved higher proportion of nausea-free patients compared with those who received ondansetron in the acute phase after MEC administration (60\% versus 57\%) ${ }^{25}$ Effective control of nausea starting from the first day of chemotherapy may contribute to maintain a good quality of life and adequate caloric intake, which in turn is related to the ability of patient to continue with the anticancer treatment. ${ }^{39}$

A number of postmarketing trials have been published that confirm efficacy of palonosetron for the prevention of CINV either alone or in combination with dexamethasone, 
with or without other drug classes, in the clinical settings of MEC, HEC and multiple-day chemotherapy. ${ }^{35,39-45,47}$

\section{Palonosetron in patients receiving oxaliplatin-based chemotherapy}

An open-label, multicenter, phase II study evaluated the safety and efficacy of intravenous single dose of palonosetron in combination with dexamethasone ( $8 \mathrm{mg}$ intravenously) on day 1 to prevent CINV in patients with colorectal cancer who were scheduled to receive oxaliplatin-based chemotherapy (Folfox-4 regimen) as an adjuvant. ${ }^{40}$ The vast majority of patients achieved $\mathrm{CR}$ and did not experience vomiting during the acute phase after chemotherapy initiation.

\section{Palonosetron in patients receiving multiple-day chemotherapy}

Einhorn et al evaluated 41 patients undergoing 5-day cisplatin-based chemotherapy for testicular cancer who received intravenous palonosetron ( $0.25 \mathrm{mg}$ once daily) $30 \mathrm{~min}$ before chemotherapy on days 1,3 , and 5 plus intravenous dexamethasone $(20 \mathrm{mg}$ ) before chemotherapy on days 1 and 2, and $8 \mathrm{mg}$ bid orally on days 6 and 7 and $4 \mathrm{mg}$ bid on day $8 .{ }^{41}$ Fifty-one percent of patients experienced no emesis throughout days 1 to 5 , while the majority (83\%) were free from emesis throughout days 6 to 9 . In addition, patients experienced no moderate to severe nausea, and did not require rescue medication.

Musso et al administered a single dose of palonosetron just before chemotherapy and dexamethasone $(8 \mathrm{mg})$ throughout the entire period of multiple-day chemotherapy. ${ }^{42}$ Forty-six patients suffering from hematologic malignancies were enrolled; $80 \%$ of them did not experience vomiting during chemotherapy administration.

\section{Palonosetron in combination with aprepitant}

An open-label, multicenter, phase II trial assessed the efficacy of intravenous single dose of palonosetron, along with dexamethasone (12 $\mathrm{mg}$ on day $1,8 \mathrm{mg}$ on days 2 and 3 ), and 3 daily oral doses of aprepitant (125 mg on day 1, $80 \mathrm{mg}$ on days 2 and 3 ) in patients receiving MEC. ${ }^{43}$ AC-based chemotherapy was the most commonly administered regimen ( $41 \%$ ). CR occurred in $88 \%$ of patients during the acute phase, and $93 \%$ experienced no emesis during the acute phase.

Herrington et al conducted a pilot, single-institution, double-blind, placebo-controlled trial that evaluated three different antiemetic regimens. ${ }^{44}$ All patients received intravenous single dose of palonosetron on day 1 and dexamethasone on days 1 to 4 after HEC administration. Arm A received aprepitant $125 \mathrm{mg}$ orally on day 1 followed by $80 \mathrm{mg}$ on days 2 to 3; arm $\mathrm{B}$ received aprepitant on day 1 and placebo on days 2 to 3 ; and arm $\mathrm{C}$ received placebo on days 1 to 3 . Primary endpoint was the proportion of patients who experienced acute and delayed emesis within each group. Seventy-five patients were included in the analysis. In either arm including aprepitant, approximately $100 \%$ of patients were free from emesis during the acute phase, while approximately $70 \%$ of patients achieved CR.

Recently, Grunberg et al evaluated the efficacy of a single-day three-drug regimen of palonosetron, aprepitant (285 mg), and dexamethasone (20 mg) before chemotherapy initiation in 41 patients receiving $\mathrm{MEC} .{ }^{45} \mathrm{CR}$ was seen in $76 \%$ of patients during the acute phase, and no emesis was reported for $100 \%$ of patients in the same period.

\section{Palonosetron in combination with olanzapine}

Olanzapine is an atypical antipsychotic drug that interacts with the dopamine, serotonin, muscarinic cholinergic, adrenergic, and histamine receptors. It has been shown to be an effective agent in controlling delayed CINV. ${ }^{46}$ The most recent trial conducted by Navari et al demonstrated high complete protection against both acute and delayed nausea. ${ }^{47}$ Forty chemotherapynaïve patients received on the day 1 of chemotherapy an antiemetic regimen consisting of dexamethasone $(8 \mathrm{mg}$ for MEC or $20 \mathrm{mg}$ for HEC), and palonosetron $(0.25 \mathrm{mg})$ before chemotherapy. Patients also began olanzapine, $10 \mathrm{mg}$ orally, on day 1 and continued $10 \mathrm{mg}$ daily for days 2 to 4 after chemotherapy administration. The vast majority of patients (97\%) experienced CR during the acute phase.

\section{Conclusions}

Prevention of CINV improves the quality of life in cancer patients, as reflected in an increased ability to complete household tasks, maintain daily functioning, and complete chemotherapeutic treatment. ${ }^{48}$ For optimal control of CINV, the patient should not experience nausea and vomiting within 24 hour following chemotherapy initiation, because control of acute CINV is a positive predictor for successful control of delayed emesis. To prevent acute emesis, antiemetic treatment should be administered just before chemotherapy and patients should be protected for up to 24 hours after chemotherapy initiation. The emetogenic potential of chemotherapeutic agents guides clinicians towards the most appropriate antiemetic prophylaxis. Current guidelines recommend 
the use of 5-HT $\mathrm{RA}_{3}$, dexamethasone, and NK-1RA to prevent CINV after administration of HEC and AC-based regimens. In patients receiving $\mathrm{MEC}$, guidelines recommend a combination of 5-HT ${ }_{3}$ RA and dexamethasone before chemotherapy initiation.

Palonosetron is a unique 5- $\mathrm{HT}_{3} \mathrm{RA}$ as it exhibits a higher binding affinity, extended half-life and a different mechanism of action compared to the first-generation agents. The antagonism of palonosetron is due to allosteric inhibition of the receptor. ${ }^{29}$ Since $5-\mathrm{HT}_{3}$ activation of the receptor is involved in emesis, an allosteric antagonist that is harder to displace would be able to control CINV for longer periods of time. Palonosetron has been shown to be more effective than older $5-\mathrm{HT}_{3} \mathrm{RAs}$ for the prevention of delayed CINV after HEC and MEC administration. ${ }^{25-27}$ However, a pooled analysis of two phase III trials with an identical noninferiority design using MEC demonstrated that palonosetron also induces a statistically significant improvement in the CR rates during the acute phase compared with pooled data from patients who received older $5-\mathrm{HT}_{3} \mathrm{RAs}^{36}{ }^{36}$ The ability of palonosetron to achieve better control of acute CINV may contribute to successful control of delayed and subsequent cycle emesis.

\section{Disclosures}

The authors declare no conflicts of interest.

\section{References}

1. Hawkins R, Grunberg S. Chemotherapy-induced nausea and vomiting: challenges and opportunities for improved patient outcomes. Clin J Oncol Nurs. 2009;13:54-64.

2. De Moor C, Cunningham RS. Improving the functional status of patients with cancer by more effectively preventing chemotherapy induced nausea and vomiting (CINV): a comparison of palonosetron (PALO) vs ondansetron (OND) or dolasetron (DOL). J Support Oncol. 2005;3:25-26.

3. Hesketh PJ. Chemotherapy-induced nausea and vomiting. $N$ Engl $J$ Med. 2008;358:2482-2494.

4. Naeim A, Dy SM, Lorenz KA, Sanati H, Walling A, Asch SM. Evidence-based recommendations for cancer nausea and vomiting. J Clin Oncol. 2008;26:3903-3910.

5. Celio L, Denaro A, Canova S, Gevorgyan A, Bajetta E. Clinical update on palonosetron in the management of chemotherapy-induced nausea and vomiting. Tumori. 2008;94:447-452.

6. Herrstedt J. Antiemetics: an update and the MASCC guidelines applied in clinical practice. Nat Clin Pract Oncol. 2008;5:32-43.

7. Hesketh PJ, Kris MG, Grunberg SM, et al. Proposal for classifying the acute emetogenicity of cancer chemotherapy. J Clin Oncol. 1997; 15:103-109.

8. Grunberg SM, Osoba D, Hesketh PJ, et al. Evaluation of new antiemetic agents and definition of antineoplastic agent emetogenicity an update. Support Care Cancer. 2005;13:80-84.

9. Roila F, Hesketh PJ, Herrstedt J. Antiemetic Subcommitte of the Multinational Association of Supportive Care in Cancer. Prevention of chemotherapy and radiotherapy-induced emesis: results of the 2004 Perugia International Antiemetic Consensus Conference. Ann Oncol. 2006;17:20-28.
10. Rubenstein EB, Slusher BS, Rojas C, Navari RM. New approaches to chemotherapy-induced nausea and vomiting: from neuropharmacology to clinical investigations. Cancer J. 2006;12:341-347.

11. Hornby PJ. Central neurocircuitry associated with emesis. Am J Med. 2001;111(8A):106S-112S

12. Trigg ME, Inverso DM. Nausea and vomiting with high-dose chemotherapy and stem cell rescue therapy: a review of antiemetic regimens. Bone Marrow Transplant. 2008;42:501-506.

13. Thompson AJ, Lummis SCR. The 5-HT3 receptor as a therapeutic agent. Expert Opin Ther Targets. 2007;11:527-540.

14. Hietala J, Nyman MJ, Eskola O, et al. Visualization and quantification of neurokinin-1 (NK1) receptors in the human brain. Mol Imaging Biol. $2005 ; 7: 262-272$.

15. Coates A, Abraham S, Kaye SB, et al. On the receiving patient perception of the side-effects of cancer chemotherapy. Eur J Cancer Clin Oncol. 1983;19:203-208.

16. Griffin AM, Butow PN, Coates AS, et al. On the receiving patient perceptions of the side effects of cancer chemotherapy in 1993. Ann Oncol. 1996;7:189-195.

17. Cohen L, De Moor C, Eisenberg, P, et al. Delayed chemotherapyinduced nausea and vomiting (CINV) remains a problem and significantly interferes with daily function (DF) in patients receiving emetogenic chemotherapy (CT) in the United States. Proc Am Soc Clin Oncol. 2003;22:739.

18. Geling O, Eichler HG. Should 5-hydroxytryptamine-3 receptor antagonists be administered beyond 24 hours after chemotherapy to prevent delayed emesis? Systematic re-evaluation of clinical evidence and drug cost implications. J Clin Oncol. 2005;23:1289-1294.

19. Girish C, Manikandan S. Aprepitant: a substance P antagonist for chemotherapy-induced nausea and vomiting. Indian $J$ Cancer. 2007;44:25-30.

20. Roila F, Donati D, Tamberi S, Margutti G. Delayed emesis: incidence, pattern, prognostic factors and optimal treatment. Support Care Cancer. 2002;10:88-95.

21. Kris MG, Hesketh PJ, Mark R, et al. American Society of Clinical Oncology Guidelines for Antiemetics in Oncology: Update 2006. J Clin Oncol. 2006;24:2932-2947.

22. National Comprehensive Cancer Network ( $\mathrm{NCCN}$ ). Clinical practice guidelines in oncology. Antiemesis. Version 1. 2009. http://www.nccn. org. Accessed January 11, 2009.

23. Navari RM. Prevention of emesis from multiple-day and high-dose chemotherapy regimens. J Nat Compr Canc Netw. 2007;5:51-59.

24. Jordan K, Hinke A, Grothey A, et al. A meta-analysis comparing the efficacy of four 5-HT3-receptor antagonists for acute chemotherapyinduced emesis. Support Care Cancer. 2007;15:1023-1033.

25. Gralla R, Lichinitser M, Van Der Vegt S, et al. Palonosetron improves prevention of chemotherapy-induced nausea and vomiting following moderately emetogenic chemotherapy: results of a double-blind randomized phase III trial comparing single doses of palonosetron with ondansetron. Ann Oncol. 2003;14:1570-1577.

26. Eisenberg P, Figueroa-Vadillo J, Zamora R, et al. 99-04 Palonosetron Study Group. Improved prevention of moderately emetogenic chemotherapy-induced nausea and vomiting with palonosetron, a pharmacologically novel 5-HT3 receptor antagonist: results of a phase III, single-dose trial versus dolasetron. Cancer. 2003;98:2473-2482.

27. Saito M, Aogi K, Sekine I, et al. Palonosetron plus dexamethasone versus granisetron plus dexamethasone for prevention of nausea and vomiting during chemotherapy: a double-blind, double-dummy, randomised, comparative phase III trial. Lancet Oncol. 2009;10:115-124.

28. Hesketh JP. New treatment options for chemotherapy-induced nausea and vomiting. Support Care Cancer. 2004;12:550-555.

29. Rojas C, Stathis M, Thomas AG, et al. Palonosetron exhibits unique molecular interactions with the 5-HT3 receptor. Anesth Analg. 2008; 107:469-478.

30. FDA Product information. http://www.accessdata.fda.gov/scripts/cder/ drugsatfda/index.cfm? fuseaction=Search.Overview $\&$ DrugName $=$ ALOXI. Accessed March 18, 2009. 
31. European Product Information. 29/01/2009 Aloxi-H-C-563-II-13. http://www.emea.europa.eu/humandocs/Humans/EPAR/aloxi/aloxi. htm. Accessed March 18, 2009.

32. Morganroth J, Parisi S, Spinelli T, Moresino C, Thorn M, Cullen MT. High-dose palonosetron does not alter ECG parameters including QTc interval in healthy subjects: results of a dose-response, double-blind, randomized, parallel E14 study of palonosetron vs moxifloxacin or placebo. Presentation at the 14th European Conference of Clinical Oncology (ECCO), September 23-27, 2007.

33. Aapro MS. Palonosetron as an anti-emetic and anti-nausea agent in oncology. Ther Clin Risk Manag. 2007;3:1009-1020.

34. Aapro MS, Grunberg SM, Manikhas GM, et al. A phase III, doubleblind, randomized trial of palonosetron compared with ondansetron in preventing chemotherapy-induced nausea and vomiting following highly emetogenic chemotherapy. Ann Oncol. 2006;17:1441-1449.

35. Yu Z, Liu W, Wang L, et al. The efficacy and safety of palonosetron compared with granisetron in preventing highly emetogenic chemotherapy-induced vomiting in the Chinese cancer patients: a phase II, multicenter, randomized, double-blind, parallel, comparative clinical trial. Support Care Cancer. 2009;17:99-102.

36. Rubenstein EB, Gralla RJ, Eisenberg P, et al. Palonosetron (PALO) compared with ondansetron (OND) or dolasetron (DOL) for prevention of acute and delayed chemotherapy-induced nausea and vomiting (CINV): combined results of two phase III trials. Proc Am Soc Clin Oncol. 2003;22:729.

37. Grunberg SM, Koeller JM. Palonosetron: a unique 5-HT3-receptor antagonist for the prevention of chemotherapy-induced emesis. Expert Opin Pharmacother. 2003;4:2297-2303.

38. Grunberg S, Vanden Burgt J, Berry S, et al. Prevention of delayed nausea and vomiting (D-CINV): carryover effect analysis of pooled data from 2 phase III studies of palonosetron (PALO). J Clin Oncol. 2004;22:A8051.

39. Lorusso V, Spedicato A, Petrucelli L, et al. Single dose of palonosetron plus dexamethasone to control nausea, vomiting and to warrant an adequate food intake in patients treated with highly emetogenic chemotherapy (HEC). Preliminary results. Support Care Cancer. 2009;DOI 10.1007/s00520-009-0611-9.
40. Giuliani F, Cilenti G, Nugnes I, et al. Palonosetron for prevention of acute and delayed nausea and vomiting induced by moderately emetogenic adjuvant folfox-4 regimen in colorectal cancer (CRC) patients: a phase II study of the Gruppo Oncologico dell'Italia Meridionale (GOIM). Eur J Cancer Suppl. 2008;6:102-106.

41. Einhorn LH, Bromes MJ, Dreicer R, et al. Palonosetron plus dexamethasone for prevention of chemotherapy induced nausea and vomiting in patients receiving multiple-day cisplatin chemotherapy for germ cell cancer. Support Care Cancer. 2007;15:1293-1300.

42. Musso M, Scalone R, Bonanno V, et al. Palonosetron (Aloxi ${ }^{\circledR}$ ) and dexamethasone for the prevention of acute and delayed nausea and vomiting in patients receiving multiple-day chemotherapy. Support Care Cancer. 2009; 17:205-209.

43. Grote T, Hajdenberg J, Cartmell A, Ferguson S, Ginkel A, Charu V. Combination therapy for chemotherapy-induced nausea and vomiting in patients receiving moderately emetogenic chemotherapy: palonosetron, dexamethasone, and aprepitant. J Support Oncol. 2006;4: 403-408.

44. Herrington JD, Jaskiewicz AD, Song J. Randomized, placebocontrolled, pilot study evaluating aprepitant single dose plus palonosetron and dexamethasone for the prevention of acute and delayed chemotherapy-induced nausea and vomiting. Cancer. 2008;112: 2080-2087.

45. Grunberg SM, Dugan M, Muss H, et al. Effectiveness of a single-day three-drug regimen of dexamethasone, palonosetron, and aprepitant for the prevention of acute and delayed nausea and vomiting caused by moderately emetogenic chemotherapy. Support Care Cancer. 2009; 17:589-594.

46. Navari RM, Einhorn LH, Loehrer PJ, et al. A phase II trial of olanzapine for the prevention of chemotherapy-induced nausea and vomiting. Support Care Cancer. 2005;13:529-534.

47. Navari RM, Einhorn LH, Loehrer PJ Sr, et al. A phase II trial of olanzapine, dexamethasone, and palonosetron for the prevention of chemotherapy-induced nausea and vomiting: a Hoosier Oncology Group study. Support Care Cancer. 2007;15:1285-1291.

48. Caro MM, Laviano A, Pichard C. Nutritional intervention and quality of life in adult oncology patients. Clinic Nutr. 2007;26:289-301.
Cancer Management and Research

\section{Publish your work in this journal}

Cancer Management and Research is an international, peer-reviewed open access journal focusing on cancer research and the optimal use of preventative and integrated treatment interventions to achieve improved outcomes, enhanced survival and quality of life for the cancer patient The journal welcomes original research, clinical \& epidemiological

\section{Dovepress}

studies, reviews \& evaluations, guidelines, expert opinion \& commentary, case reports \& extended reports. The manuscript management system is completely online and includes a very quick and fair peerreview system, which is all easy to use. Visit http://www.dovepress.com/ testimonials.php to read real quotes from published authors. 